\title{
Alternative factor analysis of the science intensity of the invested capital in the Baikal region
}

\author{
Evgeny Filatov ${ }^{1, *}$ \\ ${ }^{1}$ Irkutsk Scientific Center of the Siberian Branch of the Russian Academy of Sciences, 664033, \\ Lermontova str., 134, Irkutsk, Russia
}

\begin{abstract}
Factor analysis is the basic tool when conducting a comprehensive analysis of economic activity. In the factor analysis, the major attention is given to the research of internal reasons that form the specificity of the phenomenon under study and identification of generalized factors standing behind relevant specific indicators. The article deals with the analysis of the science intensity of the invested capital in the Baikal region of the Russian Federation. Science intensity is an important parameter for determining the efficiency of the economic activity. The author introduced into scientific circulation the following indicators: the science intensity of the invested capital, the science intensity of the gross regional product and the investment return of the gross regional product. The paper reveals the influence of factors affecting the change in the science intensity of the invested capital in the Baikal region of the Russian Federation, and provides methodological approaches to its calculation. The article presents the author's analytical and systematized statistical material for the analysis of the key indicators revealing the impact of the invested capital in the Baikal region of the Russian Federation on the change of the science intensity. The research has been carried out in the framework of the scientific project of the Irkutsk Scientific Center of the Siberian Branch of the Russian Academy of Sciences No. XI.174.1.4 "Activation of the internal development potential of regions of the resource specialization (on the example of the Baikal region)".
\end{abstract}

\section{Introduction}

The development of high technologies in the industry and the release of fundamentally new science-intensive products have now become the key factors for sustainable economic growth in most of the industrialized countries of the world. Those states that have managed to reorient their economic systems to generate knowledge, create technologies and produce science-intensive products, occupy a leading position in the world and ensure a high level of well-being of their citizens. [4]

There is a large number of characteristics and parameters to assess objects and events. Science intensity is one of them. This is a parameter that is used in the development of

* Corresponding author: johnru3000@ rambler.ru 
products and technology in the production sphere. To obtain results, high technology implies the presence of investment in research.

It is known that science intensity is one of the leading factors of the product competitiveness. This is due to the activeness of the innovation activity. As a result, science has become not just one of the production resources, but also the key factor of the economic growth.

\section{Materials and methods}

For the factor analysis of the science intensity of the invested capital, three indicators have been used: gross regional product (GRP), internal current expenditure on research and development, and investment in the fixed assets. The growth of GRP of the Baikal region of the Russian Federation looks stable, but this growth is artificial, since the main reason for this stable growth lies in the high volatility of the Russian currency.

Further, based on the methods of deterministic (functional) factor analysis developed by the author [2,3], we estimate the degree of influence of the two factors on the change of the science intensity of the invested capital of the Baikal region of the Russian Federation.

The initial data for an alternative factor analysis of the science intensity of the invested capital in the Baikal region of the Russian Federation are presented in the Table 1.

Table 1. Baseline data for the factor analysis.

\begin{tabular}{|c|c|c|c|c|c|}
\hline No. & Indicators & $\begin{array}{c}\text { Fact } \\
\text { or } \\
\text { No. }\end{array}$ & $\begin{array}{l}2014 \\
(0) *\end{array}$ & $\begin{array}{l}2015 \\
\text { (I) } * *\end{array}$ & $\underset{\star \text { Deviation }}{\text { D** }}(\Delta)$ \\
\hline 1 & $\begin{array}{l}\boldsymbol{V} \boldsymbol{R} \boldsymbol{P}-\text { gross regional product } \\
(\mathrm{GRP}) \text {, million rub. }\end{array}$ & & 1337651.2 & 1466546.1 & 128894.9 \\
\hline 2 & $\begin{array}{l}\text { VTZN }- \text { internal current } \\
\text { expenditure on research and } \\
\text { development, million rub. }\end{array}$ & & 5853.7 & 5596.4 & -257.3 \\
\hline 3 & $\begin{array}{l}\mathbf{I O K} \text { - investments in the fixed } \\
\text { assets, million rub. }\end{array}$ & & 320667 & 318577 & -2090 \\
\hline 4 & $\begin{array}{l}\boldsymbol{N} \boldsymbol{E}_{\boldsymbol{I K}} \text { - science intensity of the } \\
\text { invested capital } \\
(2 / 3)=(5 * 6)\end{array}$ & & 0.018255 & 0.017567 & -0.000688 \\
\hline 5 & $\begin{array}{l}\boldsymbol{N} \boldsymbol{E}_{V R P}-\text { science intensity of } \\
\text { GRP }(2 / 1)\end{array}$ & $F_{1}$ & 0.004376 & 0.003816 & -0.000560 \\
\hline 6 & $\begin{array}{l}\boldsymbol{I O}_{\text {VRP }}-\text { investment return of } \\
\operatorname{GRP}(1 / 3)\end{array}$ & $F_{2}$ & 4.171465 & 4.603427 & 0.431962 \\
\hline
\end{tabular}

where:

* $\mathbf{0}$ - past (basic) period (year), taken as a reference base; ** $\mathbf{I}$ - reported (current) period (year);

*** $\Delta$ - change for the period calculated as the difference between the fact and the plan (I - 0).

The author has introduced into scientific circulation the indicator of the science intensity of the invested capital $\left(\boldsymbol{N} \boldsymbol{E}_{\boldsymbol{I K}}\right)$, which is calculated as the ratio of the internal current expenditures on research and development $(V T Z N)$ to the size of investments in the fixed assets $(\mathbf{I O K})$.

The indicator of the science intensity of invested capital consists of a product of the two factors: the science intensity of GRP and the investment return of GRP.

The initial formula for the factor analysis of the science intensity of the invested capital $\left(\boldsymbol{N} \boldsymbol{E}_{I K}\right)$ will have the following form (formula 1):

$$
N E_{I K}=\frac{V T Z N}{V R P} * \frac{V R P}{I O K}=F_{1} * F_{2}
$$


The author has introduced into scientific circulation the indicator of the science intensity of GRP $\left(\boldsymbol{N} \boldsymbol{E}_{\boldsymbol{V} R \boldsymbol{P}}\right)$, which is calculated as the ratio of the internal current expenditures for the research and development $(\boldsymbol{V T Z N})$ to the size of the gross regional product ( $\boldsymbol{V R \boldsymbol { P }})$. If in 2014 the science intensity of GRP in the Baikal region of the Russian Federation was $0.44 \%$, in 2015 it decreased to $0.38 \%$.

The author has introduced the indicator of GRP investment return $\left(\boldsymbol{I} \boldsymbol{O}_{V R P}\right)$, which is calculated as the ratio of GRP $(\boldsymbol{V R P})$ to the size of investment in the fixed assets $(\boldsymbol{I O K})$. This indicator characterizes the efficiency of investment in the fixed assets. If in 2014 the investment return of the Baikal region GRP was 4.17, in 2015 it increased to 4.60.

The cumulative deviation by the resultant indicator $\left(\Delta \boldsymbol{N} \boldsymbol{E}_{I K}\right)$ is determined by the formula 2:

$$
\Delta N E_{I K}=\sum_{n=1}^{2} \Delta N E_{I K}\left(F_{n}\right)=\Delta N E_{I K}\left(F_{1}\right)+\Delta N E_{I K}\left(F_{2}\right)
$$

Auxiliary data on the comparative coefficients for the factor analysis are presented in the Table 2.

Table 2. Multiple comparative coefficients by one factor.

\begin{tabular}{|c|c|c|c|}
\hline $\begin{array}{c}\text { Comparison of } \\
\text { factors }\end{array}$ & $\begin{array}{c}\text { Signs for the } \\
\text { comparative } \\
\text { coefficients }\end{array}$ & Value & \multirow{2}{*}{$\begin{array}{c}\text { The product of the } \\
\text { coefficients (value) }\end{array}$} \\
\hline $\boldsymbol{F}_{\boldsymbol{I}(\mathrm{I})} / \boldsymbol{F}_{\boldsymbol{I}(0)}$ & $\mathrm{A}_{1}$ & 0.872018 & \multirow{2}{*}{1.00} \\
\hline $\boldsymbol{F}_{\boldsymbol{I}(0)} / \boldsymbol{F}_{\boldsymbol{I}(\mathrm{I})}$ & $\mathrm{A}_{2}$ & 1.146765 & \multirow{2}{*}{1.00} \\
\hline $\boldsymbol{F}_{\boldsymbol{2}(\mathrm{I})} / \boldsymbol{F}_{\boldsymbol{2}(0)}$ & $\mathrm{A}_{3}$ & 1.103552 & \multirow{2}{*}{$\boldsymbol{F}_{\boldsymbol{2}(0)} / \boldsymbol{F}_{\boldsymbol{2}(\mathrm{I})}$} \\
\cline { 1 - 3 }
\end{tabular}

The author's (alternative) methods of the factor analysis are presented in the Table 3.

Method No. 1.1 (formulas 1.1-1.3 in the Table 3) is based on the difference between the effective planned indicators, which is adjusted on the comparative coefficients $\left(A_{1}\right)$.

Method No. 1.2 (formulas 1.1-1.3 in the Table 3) is based on the difference between the effective actual indicators, which is adjusted on the comparative coefficients $\left(\mathrm{A}_{4}\right)$.

Method No. 2.1 (formulas 3.1-3.3 in the Table 3) is based on the ratio of the departure of the original factor to the original plan factor multiplied by the planned performance indicator, which is adjusted on the comparative coefficient $\left(\mathrm{A}_{1}\right)$.

Method No. 2.2 (formulas 4.1-4.3, in the Table 3) is based on the ratio of the departure of the original factor to the original actual factor multiplied by the actual performance indicator, which is adjusted on the comparative coefficient $\left(\mathrm{A}_{4}\right)$.

Method No. 3.1 (formulas 5.1-5.3 in the Table 3) is based on the difference between the effective actual and planned indicators, which is adjusted on the comparative coefficients $\left(\mathrm{A}_{1}\right)$.

Method No. 3.2 (formulas 6.1-6.3 in the Table 3) is based on the difference between the effective actual and planned indicators, which is adjusted on the comparative coefficients $\left(\mathrm{A}_{4}\right)$.

Method No. 4.1 (formulas 7.1-7.3 in the Table 3) is based on the ratio of the deviation of the effective factor to the difference between the effective actual and planned factors, which is adjusted on the comparative coefficient $\left(\mathrm{A}_{1}\right)$.

Method No. 4.2 (formulas 8.1-8.3 in the Table 3) is based on the ratio of the deviation of the effective factor to the difference between the effective actual and planned factors, which 
is adjusted on the comparative coefficients $\left(\mathrm{A}_{4}\right)$.

Method No. 5.1 (formulas 9.1-9.3 in the Table 3) is based on the ratio of the deviation of the effective factor to the difference between the actual performance factors, which is adjusted on the comparative coefficients $\left(\mathrm{A}_{1}\right)$.

Method No. 5.2 (formulas 10.1-10.3 in the Table 3) is based on the ratio of the deviation of the effective factor to the difference between the planned performance factors, which is adjusted on the comparative coefficients $\left(\mathrm{A}_{4}\right)$.

Table 3. Methods of the alternative factor analysis using comparative coefficients.

\begin{tabular}{|c|c|c|}
\hline \multirow{2}{*}{$\begin{array}{l}\text { Formula } \\
\text { number }\end{array}$} & \multicolumn{2}{|c|}{ Formulas / calculations } \\
\hline & Main part of the formula & $\begin{array}{l}\text { Correction } \\
\text { coefficients }\end{array}$ \\
\hline 1.1 & $\Delta \boldsymbol{N} \boldsymbol{E}_{\boldsymbol{I K}}\left(\mathrm{F}_{1}\right)=\boldsymbol{N} \boldsymbol{E}_{\boldsymbol{I K} 0} *\left(\mathrm{~A}_{1}\right)-\boldsymbol{N} \boldsymbol{E}_{\boldsymbol{I K} 0}$ & - \\
\hline 1.2 & $\Delta \boldsymbol{N} \boldsymbol{E}_{\boldsymbol{I K}}\left(\mathrm{F}_{2}\right)=\left(\boldsymbol{N} \boldsymbol{E}_{\boldsymbol{I K} 0} *\left(\mathrm{~A}_{3}\right)-\boldsymbol{N} \boldsymbol{E}_{\boldsymbol{I K} 0}\right)^{*}$ & $\mathrm{~A}_{1}$ \\
\hline 2.1 & $\Delta \boldsymbol{N} \boldsymbol{E}_{\boldsymbol{I K}}\left(\mathrm{F}_{1}\right)=\left(\boldsymbol{N} \boldsymbol{E}_{\boldsymbol{I K} \mathrm{I}}-\boldsymbol{N} \boldsymbol{E}_{\boldsymbol{I K I} \mathrm{I}} *\left(\mathrm{~A}_{2}\right)\right) *$ & $\mathrm{~A}_{4}$ \\
\hline 2.2 & $\Delta \boldsymbol{N} \boldsymbol{E}_{\boldsymbol{I K}}\left(\mathrm{F}_{2}\right)=\left(\boldsymbol{N} \boldsymbol{E}_{\boldsymbol{I K} \mathrm{I}}-\boldsymbol{N} \boldsymbol{E}_{\boldsymbol{I K} \mathrm{I}} *\left(\mathrm{~A}_{4}\right)\right) *$ & - \\
\hline 3.1 & $\Delta \boldsymbol{N} \boldsymbol{E}_{I K}\left(\mathrm{~F}_{1}\right)=\left(\Delta \mathrm{F}_{1} / \mathrm{F}_{10}\right) * \boldsymbol{N} \boldsymbol{E}_{I K} 0$ & - \\
\hline 3.2 & $\left.\Delta \boldsymbol{N} \boldsymbol{E}_{I K}\left(\mathrm{~F}_{2}\right)=\left(\Delta \mathrm{F}_{2} / \mathrm{F}_{20}\right) * \boldsymbol{N} \boldsymbol{E}_{I K 0}\right)^{*}$ & $\mathrm{~A}_{1}$ \\
\hline 4.1 & $\Delta N E_{I K}\left(\mathrm{~F}_{1}\right)=\left(\left(\Delta \mathrm{F}_{1} / \mathrm{F}_{1 \mathrm{I}}\right) * N E_{I K \mathrm{I}}\right)^{*}$ & $\mathrm{~A}_{4}$ \\
\hline 4.2 & $\Delta \boldsymbol{N} \boldsymbol{E}_{I K}\left(\mathrm{~F}_{2}\right)=\left(\Delta \mathrm{F}_{2} / \mathrm{F}_{2 \mathrm{I}}\right) * \boldsymbol{N} \boldsymbol{E}_{I K \mathrm{I}}$ & - \\
\hline 5.1 & $\Delta \boldsymbol{N} E_{I K}\left(\mathrm{~F}_{1}\right)=\left(N E_{I K I} * \mathrm{~A}_{4}\right)-N E_{I K 0}$ & - \\
\hline 5.2 & $\Delta \boldsymbol{N} \boldsymbol{E}_{\boldsymbol{I K}}\left(\mathrm{F}_{2}\right)=\left(\left(\boldsymbol{N} \boldsymbol{E}_{\boldsymbol{I K} \mathrm{I}} * \mathrm{~A}_{2}\right)-\boldsymbol{N} \boldsymbol{E}_{\boldsymbol{I K} 0}\right)^{*}$ & $\mathrm{~A}_{1}$ \\
\hline 6.1 & $\Delta \boldsymbol{N} \boldsymbol{E}_{I K}\left(\mathrm{~F}_{1}\right)=\left(\boldsymbol{N} \boldsymbol{E}_{\boldsymbol{I K} \mathrm{I}}-\left(\boldsymbol{N} \boldsymbol{E}_{I K} 0^{*} \mathrm{~A}_{3}\right)\right) *$ & $\mathrm{~A}_{4}$ \\
\hline 6.2 & $\Delta \boldsymbol{N} \boldsymbol{E}_{I K}\left(\mathrm{~F}_{2}\right)=\boldsymbol{N} \boldsymbol{E}_{I K \mathrm{I}}-\left(\boldsymbol{N} \boldsymbol{E}_{I K} 0^{*} \mathrm{~A}_{1}\right)$ & - \\
\hline 7.1 & $\Delta \boldsymbol{N} \boldsymbol{E}_{I K}\left(\mathrm{~F}_{1}\right)=\Delta \boldsymbol{N} \boldsymbol{E}_{I K}-\left(\boldsymbol{N} \boldsymbol{E}_{I K I}-\left(\boldsymbol{N} \boldsymbol{E}_{I K} 0^{*} \mathrm{~A}_{1}\right)\right.$ & - \\
\hline 7.2 & $\Delta \boldsymbol{N} \boldsymbol{E}_{I K}\left(\mathrm{~F}_{2}\right)=\Delta \boldsymbol{N} \boldsymbol{E}_{I K}-\left(\boldsymbol{N} \boldsymbol{E}_{I K \mathrm{I}}-\left(\boldsymbol{N} \boldsymbol{E}_{I K} 0^{*} \mathrm{~A}_{3}\right)\right)^{*}$ & $\mathrm{~A}_{1}$ \\
\hline 8.1 & $\Delta \boldsymbol{N} E_{I K}\left(\mathrm{~F}_{1}\right)=\Delta \boldsymbol{N} E_{I K}-\left(\left(\boldsymbol{N} E_{I K I} * \mathrm{~A}_{2}\right)-\boldsymbol{N} E_{I K}\right) *$ & $\mathrm{~A}_{4}$ \\
\hline 8.2 & $\Delta N E_{I K}\left(\mathrm{~F}_{2}\right)=\Delta N E_{I K}-\left(\left(N E_{I K I} * \mathrm{~A}_{4}\right)-N E_{I K}\right)$ & - \\
\hline 9.1 & $\Delta N E_{I K}\left(\mathrm{~F}_{1}\right)=\Delta N E_{I K}-\left(N E_{I K \mathrm{I}}-\left(N E_{I K \mathrm{I}} * \mathrm{~A}_{4}\right)\right)$ & - \\
\hline 9.2 & $\Delta \boldsymbol{N} \boldsymbol{E}_{I K}\left(\mathrm{~F}_{2}\right)=\Delta \boldsymbol{N} \boldsymbol{E}_{I K}-\left(\boldsymbol{N} \boldsymbol{E}_{I K \mathrm{I}}-\left(\boldsymbol{N} \boldsymbol{E}_{I K \mathrm{I}} * \mathrm{~A}_{2}\right)\right)$ & $\mathrm{A}_{1}$ \\
\hline 10.1 & $\Delta \boldsymbol{N} \boldsymbol{E}_{I K}\left(\mathrm{~F}_{1}\right)=\Delta \boldsymbol{N} \boldsymbol{E}_{I K}-\left(\left(\boldsymbol{N} \boldsymbol{E}_{I K} 0^{*} \mathrm{~A}_{3}\right)-\boldsymbol{N} \boldsymbol{E}_{\boldsymbol{I K} 0}\right)^{*}$ & $\mathrm{~A}_{4}$ \\
\hline 10.2 & $\Delta \boldsymbol{N} \boldsymbol{E}_{\boldsymbol{I K}}\left(\mathrm{F}_{2}\right)=\Delta \boldsymbol{N} \boldsymbol{E}_{\boldsymbol{I K}}-\left(\left(\boldsymbol{N} \boldsymbol{E}_{\boldsymbol{I K} 0} * \mathrm{~A}_{1}\right)-\boldsymbol{N} \boldsymbol{E}_{\boldsymbol{I K} 0}\right)$ & - \\
\hline
\end{tabular}

\section{Results}

The result by the methods $1.1,2.1,3.1,4.1,5.1$ is presented in the Table 4 ; the result by the methods 1.2, 2.2, 3.2, 4.2, 5.2 is presented in the Table 5 .

Table 4. Result by the methods 1.1, 2.1, 3.1, 4.1, 5.1.

\begin{tabular}{|c|l|c|l|c|}
\hline No. & Main part of the formula & \multicolumn{2}{|c|}{ Correction coefficients } & Result \\
\hline 1 & $\Delta N E_{I K}\left(\mathrm{~F}_{1}\right)=-0.002336$ & - & & -0.002336 \\
\hline 2 & $\Delta \boldsymbol{N} E_{I K}\left(\mathrm{~F}_{2}\right)=0.001890$ & 0.872018 & $\mathrm{~A}_{1}$ & 0.001648 \\
\hline & $\mathbf{- 0 . 0 0 0 4 4 6}$ & & $\mathbf{- 0 . 0 0 0 6 8 8}$ \\
\hline
\end{tabular}


Table 5. Result by the methods 1.2, 2.2, 3.2, 4.2, 5.2.

\begin{tabular}{|c|c|c|c|c|}
\hline No. & Main part of the formula & \multicolumn{2}{|c|}{ Correction coefficients } & Resut \\
\hline 1 & $\Delta \boldsymbol{N} \boldsymbol{E}_{I K}\left(\mathrm{~F}_{1}\right)=-0.002578$ & 0.906165 & $\mathrm{~A}_{4}$ & -0.002336 \\
\hline \multirow[t]{2}{*}{2} & $\Delta \boldsymbol{N} \boldsymbol{E}_{\boldsymbol{I K}}\left(\mathrm{F}_{2}\right)=0.001648$ & - & & 0.001648 \\
\hline & -0.000930 & & & -0.000688 \\
\hline
\end{tabular}

The factor analysis makes it possible to obtain a quantitative estimate of the influence of the factors' deviations on the deviation of the value of the indicator under study. As it is seen from the final result in the Tables 1, 4, 5, the goal of the analysis is achieved - the determination of the influence of factors is revealed without deviations.

Based on the results of the analysis, the following factors influenced the change in the science intensity of invested capital $\left(\Delta \boldsymbol{N} \boldsymbol{E}_{\boldsymbol{I K}}\right)$ of the Baikal region of the Russian Federation in the amount of $-0.0688 \%$ :

- decrease in the science intensity of GRP of the Baikal region of the Russian Federation $\left(\boldsymbol{F}_{1}\right)$ by -0.00056 reduced the indicator under study by $-0.2336 \%$;

- increase in investment return of GRP of the Baikal region of the Russian Federation $\left(\boldsymbol{F}_{2}\right)$ by 0.431962 increased the indicator under study by $+0.1648 \%$.

According to the results of the analysis, it is evident that in 2015 compared to 2014 there was an insignificant (almost zero) decrease in the science intensity of the economy of the Baikal region of the Russian Federation. This, in turn, allows suggesting that in 2015 after the financial crisis, no economic recovery in Russia as a whole and in the Baikal region in particular is observed.

\section{Discussion}

The low volume of investments in science in the Russian Federation as a whole, and in the Baikal region in particular, forms insignificant indicators of the science intensity of the invested capital.

In addition, it can be concluded that the Russian economy entered a stage of stagnation, and the competitiveness of the Russian economy on the international arena decreased. The level of the material state of life of the population of the Russian Federation sharply decreased. By February 2016, due to the significant devaluation of the ruble, the average annual salary of an average Russian citizen (in terms of the US dollars) was inferior to that of in the PRC [5].

The following causes of the currency crisis in Russia at the end of 2014 are officially recognized: the global decline of the oil prices and the tightening of the anti-Russia economic sanctions due to the accession of the Crimea. But apart from the officially announced reasons for the currency crisis, there is also the activity of the currency speculators.

\section{Conclusion}

An innovative type of the economic development is a prerequisite for the sustainable economic growth. Therefore, an innovative type of the economic development is a necessary condition for the sustainable growth and the exit from the stagnation. To develop an innovative type of economic development, it is necessary to create a clear strategy for the country's innovative development.

The structural crisis, initiated by the global economic imbalance, raised the question about 
the fundamental reason for the crisis of the existing paradigm of production and consumption, the solution of which is only possible under the condition of the accelerated increase of the science intensity of contemporary industrial production, and also the increase of the high technology segment of the national industry at the rates exceeding macroeconomic dynamics [1].

\section{References}

1. D. I. Gorodetsky, Formation of the science-intensive structure of Russian industry in the system of long-term economic growth factors (Doctoral Dissertation, 2010)

2. E. A. Filatov, Methodology of evaluation and analysis of the performance of commercial organizations (2015

3. E. A. Filatov, Methods of deterministic (functional) factor analysis (2011)

4. T. G. Sadovskaya, V. A. Dadonov, P. A. Drogovoz, Business Analysis, 288 (2006).

5. Y. V. Ragulina, A. V. Bogoviz, A. N. Alekseev, Advances in Intelligent Systems and Computing, 622, 568-573 (2018) 